\title{
HISTOPLASMOSE CUTÂNEA EM FELINO - RELATO DE CASO
}

\author{
CUTANEOUS HISTOPLASMOSIS IN FELINE: A CASE REPORT
}

\author{
K. L. PINTO ${ }^{\text {I* }}$, N. S. CUSTÓDIO², P. T. GIMENES ${ }^{2}$, C. M. GORRICHO ${ }^{2}$, F. TADEU JÚNIOR ${ }^{2}$, \\ R. L. SALOMÃO ${ }^{3}$, A. G. CAMPOS ${ }^{4}$, E. L. PALAZZO ${ }^{4}$
}

\section{RESUMO}

A Histoplasmose é uma zoonose, causada pelo fungo Histoplasma capsulatum, sendo transmitida a partir da inalação de esporos, encontrados em fezes de morcegos, aves e solos ricos em matéria orgânica. No Brasil, há registros de surtos da doença nas regiões dos estados de São Paulo, Rio de Janeiro, Espírito Santo, Mato Grosso e Minas Gerais. Este trabalho objetivou relatar um caso de um felino, SRD, com sete anos de idade, macho, atendido no Hospital Veterinário da Faculdade Doutor Francisco Maeda FAFRAM diagnosticado com histoplasmose cutânea. O animal deu entrada no Hospital Veterinário apresentando alopecias e feridas ulcerativas por todo o corpo, principalmente em região de face, além de apatia, perda de peso progressiva e linfadenomegalia, com demais parâmetros normais e histórico de acesso à rua e envolvimento com brigas. Sugeriu-se coleta de fragmento de pele para análise histopatológica. $\mathrm{Na}$ análise histopatológica observou-se epiderme com necrose e infiltrado neutrofílico degenerado, áreas de hiperplasia, infiltrado inflamatório piogranulomatoso e macrófagos espumosos fagocitando estruturas compatíveis com fungos leveduriformes, caracterizando dermatite necro granulomatosa e histoplasmose. $\mathrm{O}$ animal foi submetido ao tratamento com itraconazol $\left(5 \mathrm{mg} \mathrm{kg}^{-1}, \mathrm{BID}\right)$, sem melhora no quadro clínico após 30 dias. O proprietário, que também já estava apresentando sintomatologia da doença, optou pela eutanásia do animal que já apresentava dificuldade respiratória e possível disseminação para trato respiratório. Sendo assim, podemos concluir que o exame histopatológico é fundamental no diagnóstico de histoplasmose e que, neste caso, o tratamento não foi eficaz, ocorrendo o contágio da doença para o homem.

PALAVRAS-CHAVE: FERIDAS. ZOONOSE. GATO. HISTOPLASMA.

ÁREA TEMÁTICA: Doenças infecciosas 